\title{
Parked Car Interior Temperature Investigation in Brunei Darussalam
}

\author{
M. Rakib Uddin, and Muhammad Faiz bin Haji Ya'akub
}

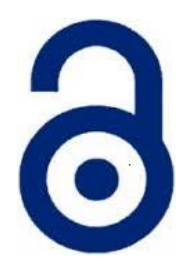

Received: 04 February 2020

Accepted: 26 March 2020

Published: 30 March 2020

Publisher: Deer Hill Publications

(c) 2020 The Author(s)

Creative Commons: CC BY 4.0

\begin{abstract}
When a car is parked under the sunlight for a long period of time, solar radiation enters the vehicle through the car glass and becomes trapped inside the car. This causes the cabin interior air temperature to increase and this is especially noticeable in tropical countries with hot and humid climates that are situated near the equator like Brunei Darussalam. Aside from causing thermal discomfort to the passengers inside the car, degradation of the surfaces of the car interior may also be accelerated. This paper aims to demonstrate the severity of the heat by recording a number of temperature measurements in a certain period of time for two different types of cars, under three different conditions for each car and comparing them to the ambient temperature. It is observed that the interior temperature depends on the design of the car. We experimented temperature measurements for two types of car models, i.e., saloon and SUV models. Saloon car is design such as way that its interior volumes space is smaller than the SUV designed car. The smaller interior volume spaced Saloon car exhibits higher maximum temperature of $68.7^{\circ} \mathrm{C}$ whereas the larger interior volume spaced SUV car exhibits maximum temperature of $59.4^{\circ} \mathrm{C}$ under fully exposed to sun with same environmental conditions.
\end{abstract}

Keywords: Car interior air temperature; ambient temperature; thermal discomfort

\section{INTRODUCTION}

Prolong exposure to sunlight can significantly increase the temperature inside a parked car when the car's engine is off. This is due to the solar radiation that enters the vehicle through the window panels and becomes partially trapped within the cabin of the car. This causes the temperature to rise substantially when the occupants get back into the parked car. The main issue that comes from the highly elevated temperature is thermal discomfort to the passengers. Aside from that, it may also accelerate the degradation of the surfaces of the car interior after being exposed to sunlight for so long and are subjected to stress from the increasing heat. The main purpose of this investigation is to find out the variation of interior air temperature in relation to the ambient temperature with respect to time. To prove that the interior air temperature of the vehicle does indeed rise significantly, a series of tests has been devised to monitor and gather some data from inside two different types of cars, under three different conditions of each car. The objectives of this paper are to; take multiple measurements of the interior air temperature of the car within certain period of time of the day; repeat the process for different types of sunlight exposure and for different types of cars; investigate the relationship of the interior air temperature variation in relation to the ambient temperature outside the car by graphically showing the characteristics.

In May 2014, W. A. A. Fadeel et al, has made a journal about Temperature Variations in a Parked Car Exposed to Direct Sun during Hot and Dry Climates in Aswan, Egypt [1]. They have concluded that the temperature levels inside a parked car can increase to as much as $80^{\circ} \mathrm{C}$. In a similar study, M.S.F. Mansor et al. [2] concluded that the trapped and accumulated heat causes the temperature inside a car to reach up to $50{ }^{\circ} \mathrm{C}$. This has caused many fatalities being reported as a result of internal car heat. Russell Manning and John Ewing had also made a report about Temperature in Cars survey [3]. Their report touches on several ways of investigating the temperature of inside a car. On vehicles having different paint colours, they have concluded that the rate of temperature increase inside the cabin is similar, regardless of paint colour. On having the windows slightly open versus having it fully closed, it was concluded that the peak temperature was still dangerously high for both cases but the one with windows slightly open has a slower temperature rise inside the cabin of the car. Lastly, their temperature investigation also include the use of sunshades and tinted films inside the test car, which both results in only an insignificant difference to the rate of temperature rise with only a marginal difference to the final peak cabin temperatures.

M. Pešek, Brno University of Technology has made an article about The Temperature field's measurement of air in

M. Rakib Uddin $ه$ and Muhammad Faiz bin Haji Ya’akub

Electrical and Electronics Engineering Programme Area, Faculty of Engineering

Universiti Teknologi Brunei, Brunei Darussalam

Email: rakib.uddin@utb.edu.bn

Reference: Rakib Uddin, M. and Ya’akub, M. F. (2020). Parked Car Interior Temperature Investigation in Brunei Darussalam. International Journal of Engineering Materials and Manufacture, 5(1), 12-18. 
the car cabin by infrared camera [4]. In October 2013, Sudhir Chitrapady Vishweshwara et al. made a journal about the Study of Excessive Cabin Temperatures of the Car Parked in Oman and its Mitigation [5]. Their study has concluded that on a bright sunny day, the vehicles cabin temperature rises to about $22^{\circ} \mathrm{C}$ above ambient temperature. However, upon installing the mitigation, the difference between cabin and outside temperature was greatly reduced. In August 2015, an independent test was carried out by Doug DeMuro on the impact of car colour to the interior temperature [6]. In the heat, the colour of the car can have an impact: with black cars heating up quicker and cooling down slower than white ones. The black car's cabin measured a scorching $130^{\circ} \mathrm{F}\left(54^{\circ} \mathrm{C}\right)$, while the white car's interior registered only $113^{\circ} \mathrm{F}\left(45^{\circ} \mathrm{C}\right)$. He discovered that the interior of the white car cooled to $84^{\circ} \mathrm{F}\left(29^{\circ} \mathrm{C}\right)$ after 10 minutes of turning the air-conditioning back on, while the black car was still at $91^{\circ} \mathrm{F}\left(27^{\circ} \mathrm{C}\right)$. Another study by $\mathrm{H}$. $\mathrm{H}$. Al-Kayiem et al [7], mentioned that the thermal condition inside the car forces the car user to wait 2-5 minutes to cool down the hot interior air and this increases fuel consumption. Several studies also found that the heat inside the car can cause health concerns as mentioned in the findings by C. McLaren et al [8] and A. Grundstein et al. [9].

In this paper, we aim to demonstrate the severity of the heat by recording a number of temperature measurements in a certain period of time for two different types of cars, under three different conditions for each car and comparing them to the ambient temperature in Brunei Darussalam. We found that the interior air temperature can reach a maximum of $68.7^{\circ} \mathrm{C}$ when the car is fully exposed to sunlight. Even when the car is fully shaded from the top, the temperature can reach a high of $43^{\circ} \mathrm{C}$. The rest of the paper is organized as below: in section 2, the temperature measurement investigation setup is described. In section 3 of this paper, the analysis of temperature investigation data was explained. Lastly, section 4 describes the conclusion of this paper.

\section{TEMPERATURE INVESTIGATION SETUP}

To investigate the temperature characteristics, specialised equipment and proper steps and procedure is needed.

\subsection{Device under Testing}

The test cars used were a black coloured 2010 Ford Fiesta for the Saloon experiment and a light-green coloured 2004 Ssangyong Rexton for the SUV experiment. The Ford Fiesta is a compact saloon/sedan type of car that can accommodate 5 people, while the Ssangyong Rexton is a Large-size 7-seater SUV that has a very large cabin size, as shown in Fig 1 and 2.

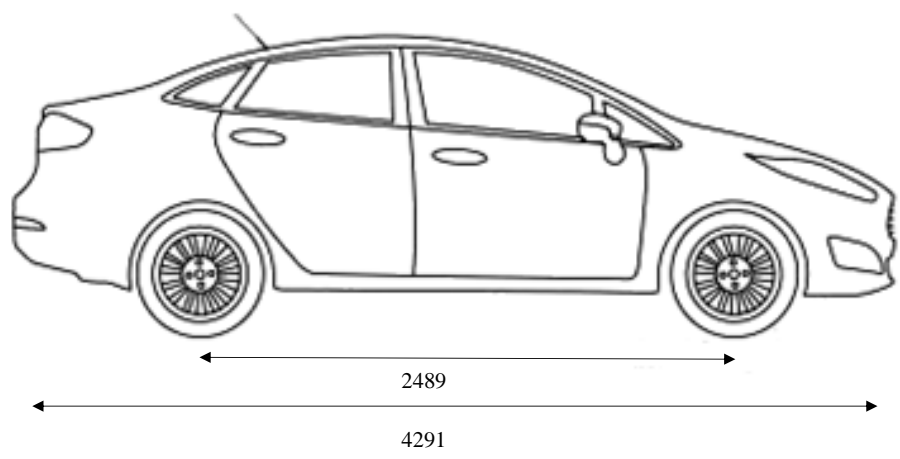

Figure 1. Schematic of a 2010 Ford Fiesta saloon (dimensions are in $\mathrm{mm}$ )
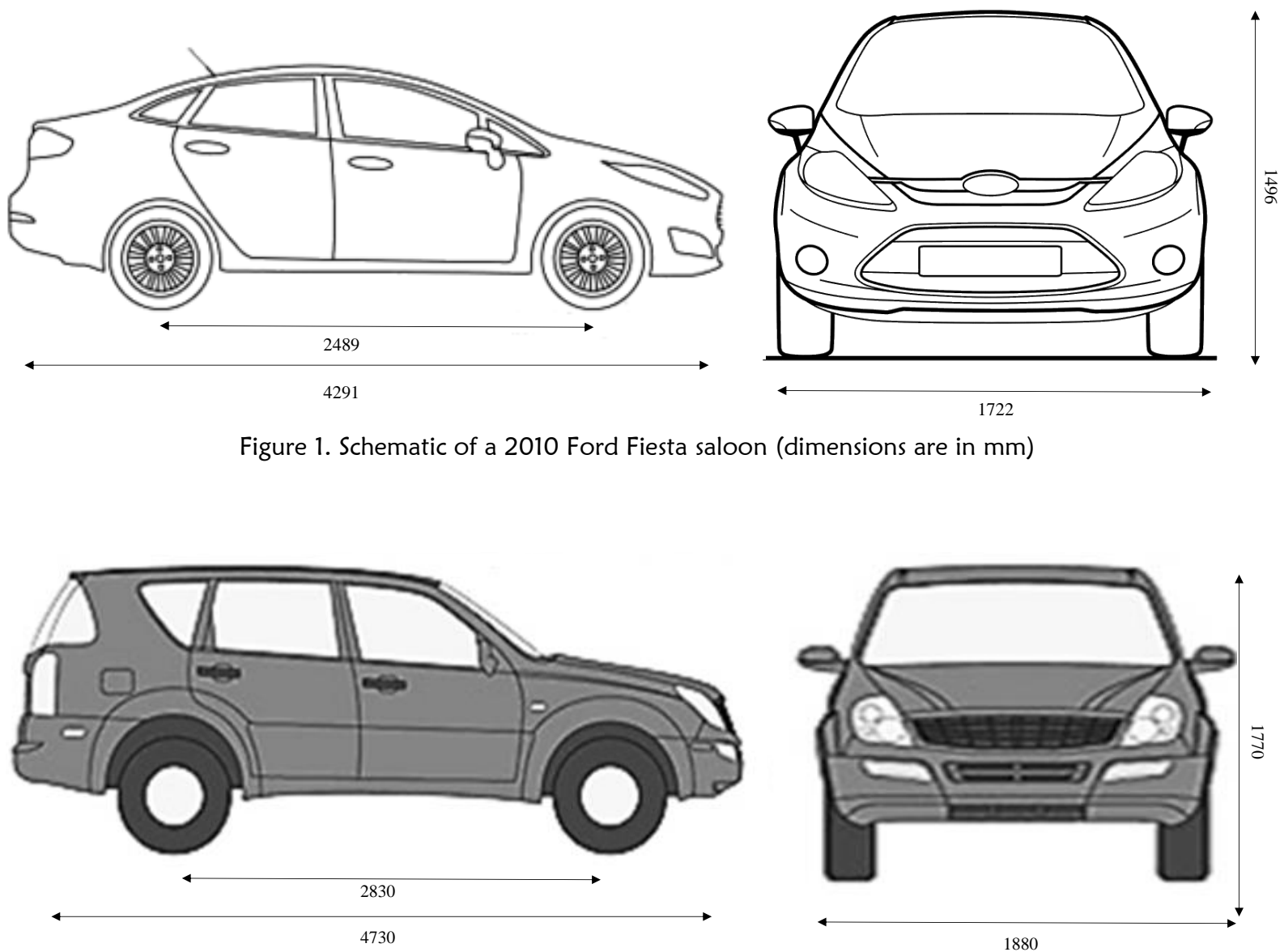

Figure 2. Schematic of a 2004 Ssangyong Rexton SUV (dimensions are in mm) 


\subsection{Measuring Equipment}

The test was carried out using a temperature data logger made by the company Elitech. Officially called the Elitech USB Temperature Data Logger RC-5, it has a wide measuring range of $-30^{\circ} \mathrm{C}$ to $70^{\circ} \mathrm{C}$, with a resolution of $0.1^{\circ} \mathrm{C}$ and an accuracy of $\pm 0.5^{\circ} \mathrm{C}$. It uses an internal NTC thermal resistor as its sensor as the unit itself is IP67 rated water resistance. The RC-5 can automatically gather temperature data over a set amount of time and can be transferred using the built-in USB connection. The main reason for using this specific equipment is due to its wide temperature range and robust hardware, which makes it very suitable for this application. The data logger is also specialised for measuring temperature inside a confined or enclosed space such as a room or a car.

\subsection{Test Area and Period}

The cars were tested at a private and open land area in located in Bandar Seri Begawan, Brunei Darussalam. The location has a very large open space that can ensure that the tested cars are not shaded when the temperature is logged. The test was carried out at random days where there was generally sunlight throughout the day from 9 AM to 5 PM for each day, from December of 2017 until the March of 2018.

\section{EXPERIMENTAL METHOD}

Before carrying out the temperature measurements, the RC-5 data logger's parameters must be set using a computer through the given proprietary software by Elitech. First, both the RC-5 data loggers must be calibrated properly. Although they are claimed to be pre-calibrated by Elitech from the factory, sometimes they have some little tolerance that can cause some discrepancy. In this case, the data logger was then calibrated using the given proprietary software using a known already calibrated SHTC1 sensor as a basis of control. This is shown in Fig 4 and 5. Next, the measuring parameters are then set using the same software. In this case, the real-time clock was synced with the correct time on the computer and the time interval was then set for 5 minutes. This means that the data logger will automatically record and save the current temperature every 5 minutes.

The RC- 5 data logger was then put inside the car and was suspended by a small rope in the approximate centre of the interior between the font seats of the car as to avoid contact with the interior surfaces. This is shown in Fig 6 . The purpose of this is for measuring only the interior air temperature of the vehicle, rather than surface temperature of the car interior. It was placed inside the car for at least 10 to 15 minutes before 9AM to ensure that the air temperature inside the car settles down after the door was being opened for the installation of the data logger. The data logger was kept inside the car for the total duration of 8 hours. It was important to ensure that none of the door or windows were open throughout the whole duration.

The tests were carried out in three different conditions for each types of cars. On Condition 1; the car was parked in an open area, more than 25 metres from any buildings or trees to ensure that the car will not be shaded in any way at any time from $9 \mathrm{AM}$ to $5 \mathrm{PM}$, as shown in Fig 7. On Condition 2; the car was parked relatively near to a building, around less than 10 metres to the nearest building, as shown in Fig 8 . In this case, the car was partially shaded at certain time of day, except for mid-day where the car was fully exposed and not shaded because the sun is directly above the car. On Condition 3; the car was parked under an open type garage or shed where the car is only fully shaded from the top but not from the sides or the front, as shown in Fig 9. For each condition, at least five days' worth of measurements were taken for each car for each conditions to make a sizeable sample of data.

\section{EXPERIMENTAL RESULTS AND ANALYSES}

To compare the temperature data obtained from the RC-5 temperature data logger, there must also be data for the ambient temperature during the same period of time in the day. The samples for ambient temperature were taken from the Weather Underground website for the hourly forecast temperatures for each day. Condition 1 can be considered as the worst case scenario for temperature increase because the car is fully exposed for the total duration of 8 hours in direct sunlight and the graph in Figure 10 reflects that. After just 1 hour from 9:00AM, the interior air temperature already rose by about $18.6^{\circ} \mathrm{C}$ (from $32^{\circ} \mathrm{C}$ to $50.6^{\circ} \mathrm{C}$ ) which is respresents a sizable $58.1 \%$ increase.

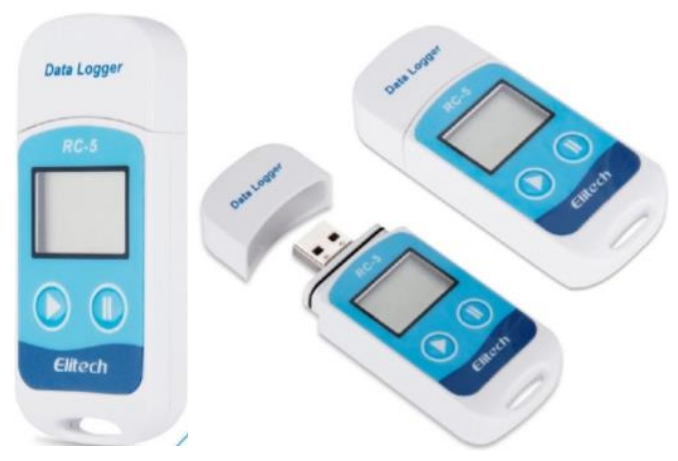

Figure 3. RC-5 Temperature Data Logger

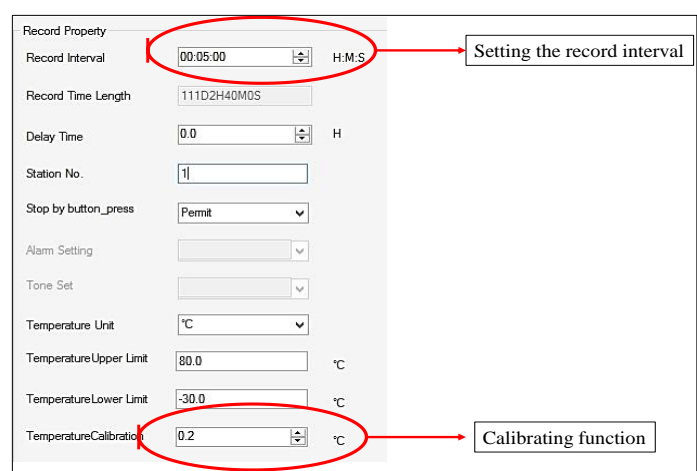

Figure 4. Calibrating and setting the time interval parameter 


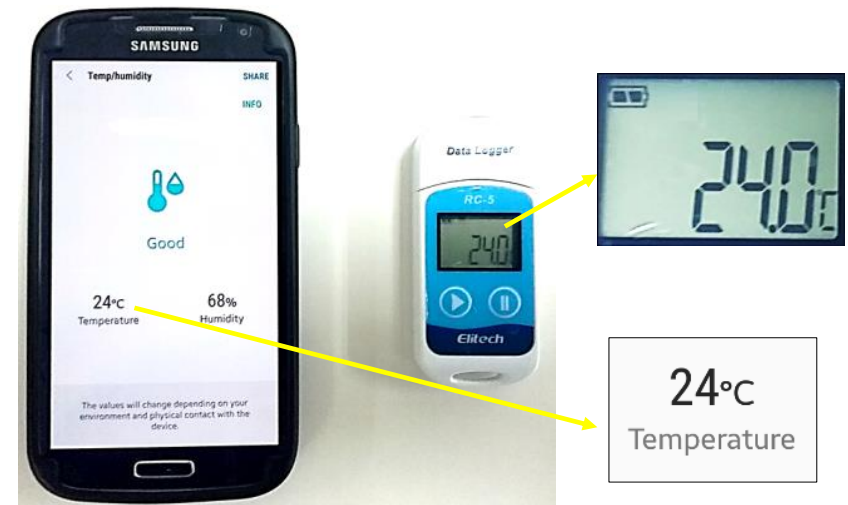

Figure 5. Calibrated data logger

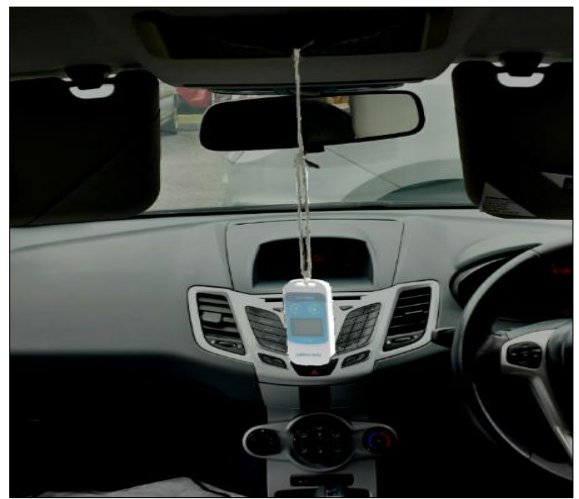

Figure 6. Placement of equipment inside the car

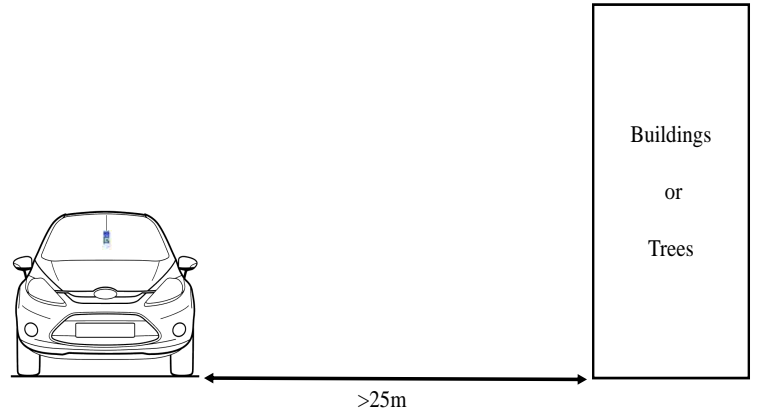

Figure 7. Condition 1, car is fully exposed to sunlight and located more than $25 \mathrm{~m}$ from any buildings

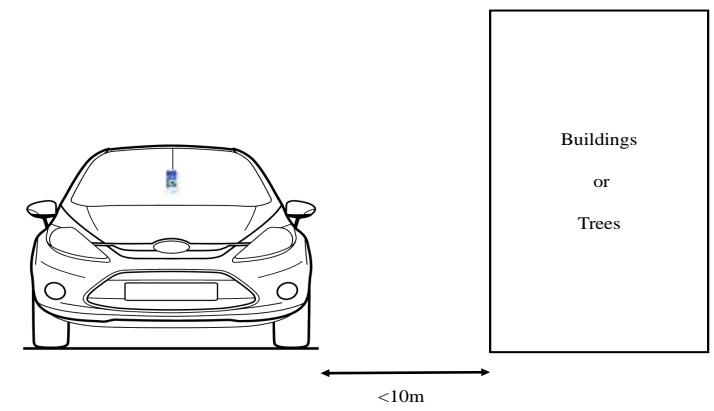

Figure 8. Condition 2, car is partially shaded at certain times and located less than $10 \mathrm{~m}$ from any buildings
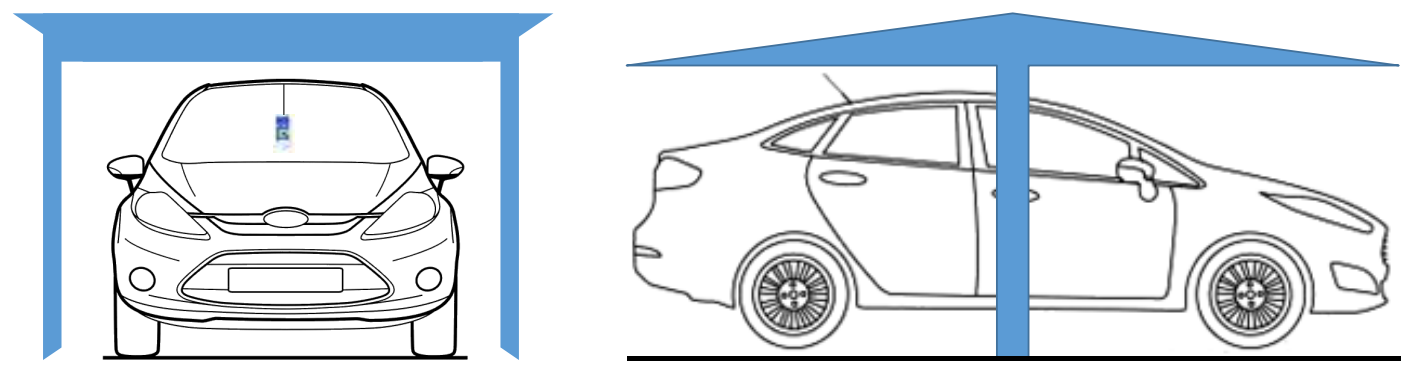

Figure 9. Condition 3, car is shaded under open type shed

Also by observing the graph, the interior air temperature usually reached within $10 \%$ of the maximum at around 1:00PM and stays about constant until around 4:00PM where the temperature starts to fall off because the decrease in sunlight intensity. The highest interior air temperature of $68.7^{\circ} \mathrm{C}$ obtained was on March 23 and 24 at exactly $2: 30$ PM. At that exact time, the ambient temperature was $31^{\circ} \mathrm{C}$ and when compared with the interior air temperature of $68.7^{\circ} \mathrm{C}$, the percentage difference was a significant $45.1 \%$. As for the case of the SUV type car for Condition 1 as shown in Fig 11, the initial interior air temperature seems to start of higher than that from the Saloon type car. This may be due to the bigger surface area of the windows of the SUV which leads to more sunlight entering the car especially during the morning since the data logger may be subjected from direct sunlight. The interior temperature generally reached maximum at around 2:00PM, which was similar to that of the Saloon. However, the maximum temperature of $59.4^{\circ} \mathrm{C}$ was much lower than that from the Saloon $\left(68.7^{\circ} \mathrm{C}\right)$.

As for Condition 2 as shown in Fig 12, the interior air temperature was very close to the outside ambient temperature even after 2 hours, from 9:00AM to 11:00AM. Only after 11:00AM does the interior air temperature saw a sharp increase as the car was being directly exposed to the sun approaching midday. The maximum interior air temperature was usually reached at around 1:00PM to 2:00PM. From then onwards, the temperature starts to slowly decrease and then at around 4:00PM, the interior temperature starts to cool down quickly. The maximum interior air temperature reached was $57.6^{\circ} \mathrm{C}$. 


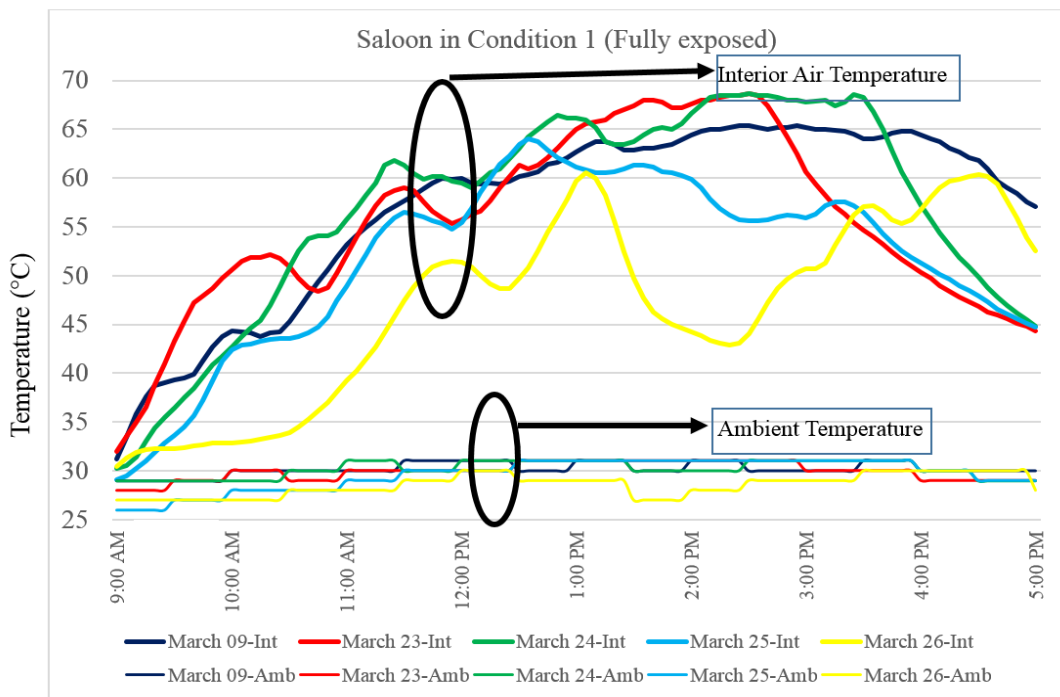

Figure 10. Condition 1 for Saloon type

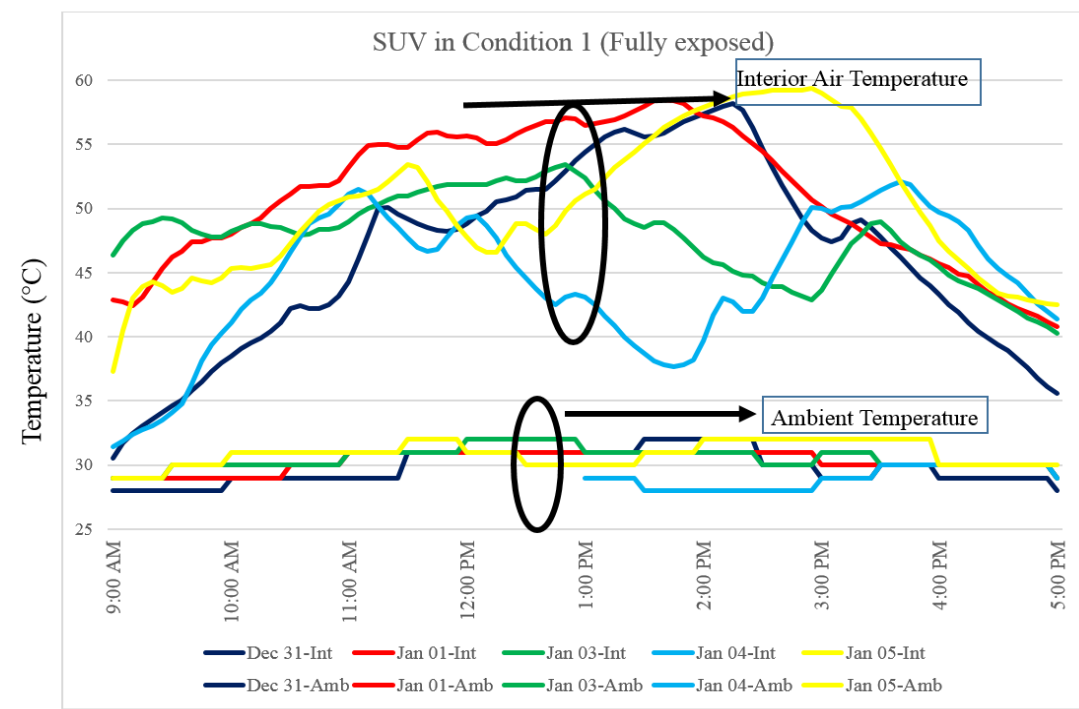

Figure 11. Condition 1 for SUV type

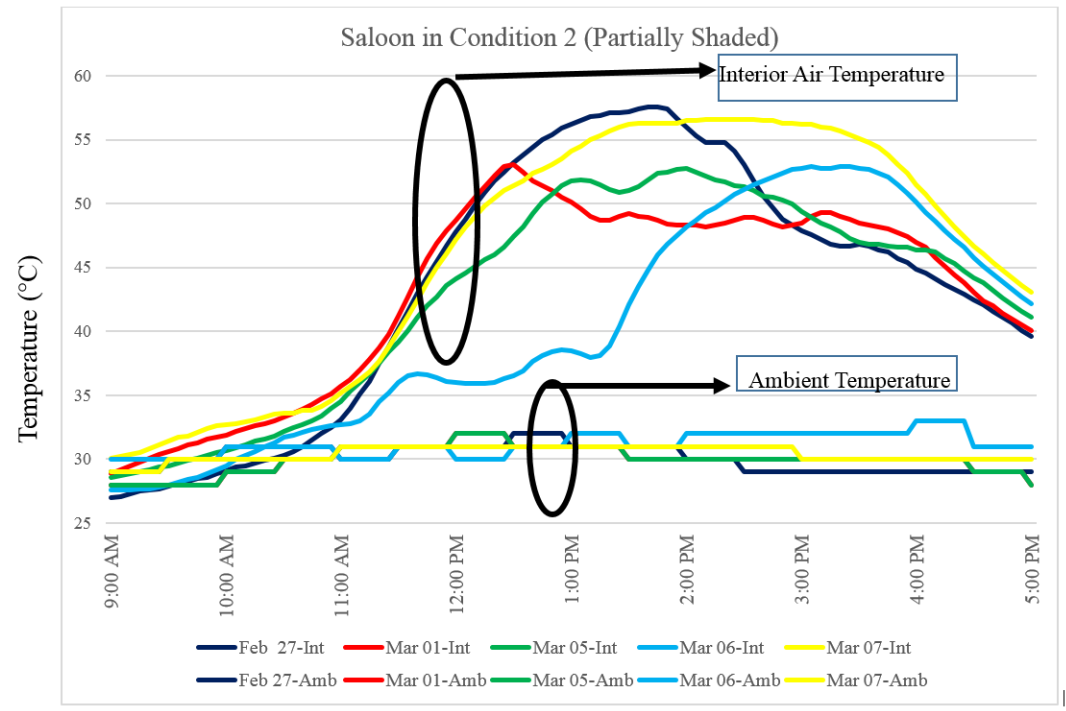

Figure 12. Condition 2 for Saloon type 
For the SUV type in Condition 2, the characteristic was similar to that of the Saloon but generally reaches its maximum interior air temperature a little later at around past 2:00PM. Again the interior temperature saw a sharp decrease in temperature after 4:00PM. The maximum interior air temperature reached was $57.1^{\circ} \mathrm{C}$, about the same with the Saloon. This is shown in Fig 13. For Condition 3, the rise in interior air temperature was significantly slower when compared to Condition 1 and 2 . In some cases, it could take up to 2 hours to even exceed $30^{\circ} \mathrm{C}$ as seen in Figure 14 . Looking at the graphs for January 17, the interior air temperature reached its maximum at the same time as the ambient temperature, but even at its peak there was only a mere $6.2 \%$ difference. The maximum interior air temperature reached was $34.1^{\circ} \mathrm{C}$.

As for the SUV in Condition 3 as shown in Fig 15, the initial rise has similar characteristics to that of the Saloon, however the interior air temperature inside the SUV kept on rising and generally hits the peak around after 3:00PM. The continued rise in temperature might be caused by the bigger surface area of the window panels of the SUV, which allows reflected sunlight to enter the car from the sides even when the car is fully shaded from the top. Then as with all the other Conditions, the temperature drops significantly after 4:00PM, the same can be said for the ambient temperature as well. When compared to the Saloon in the same conditions, while the Saloon's interior air temperature stays generally constant after 1:00PM, the SUV's interior temperature kept on rising, reaching a maximum of $43^{\circ} \mathrm{C}$, which is a significant $28 \%$ percentage difference compared to the ambient temperature.

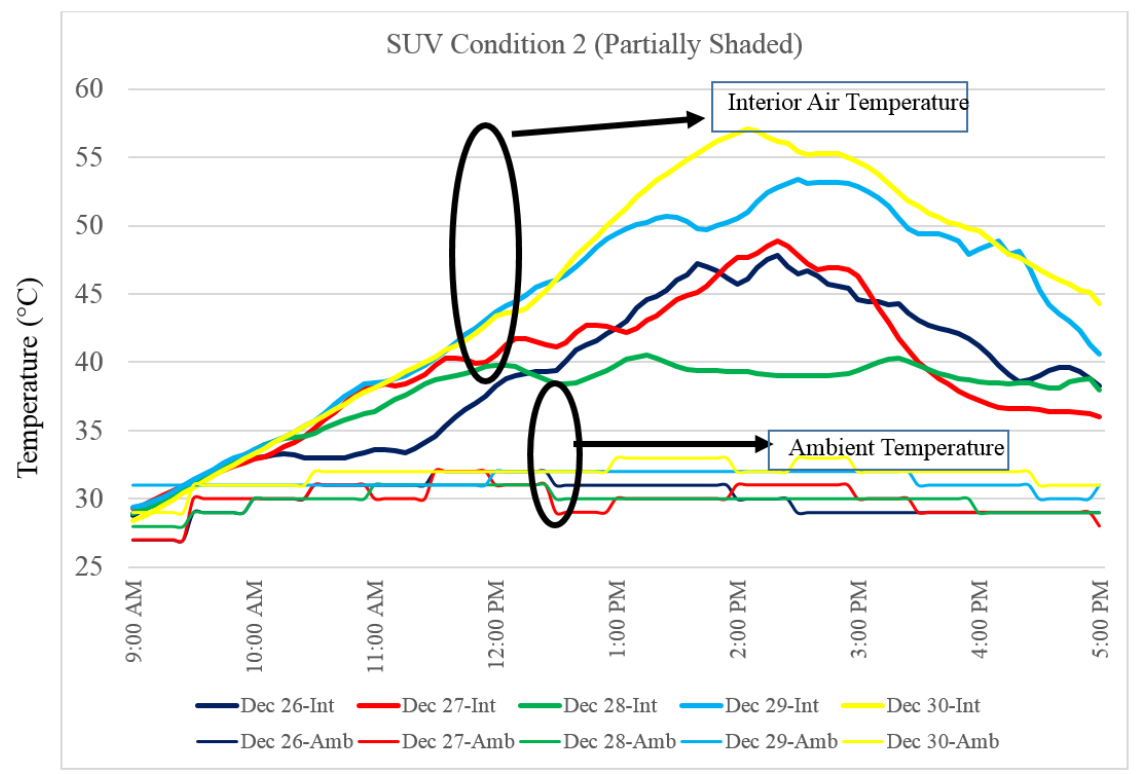

Figure 13. Condition 2 for SUV type

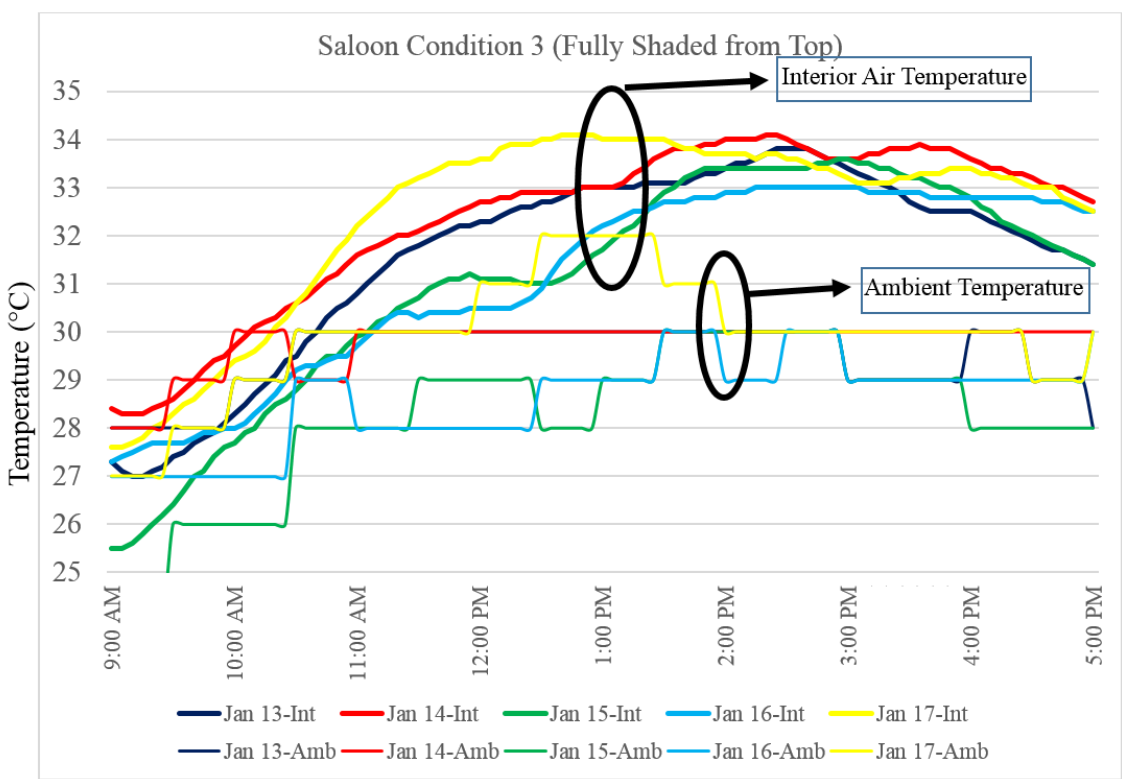

Figure 14. Condition 3 for Saloon type 


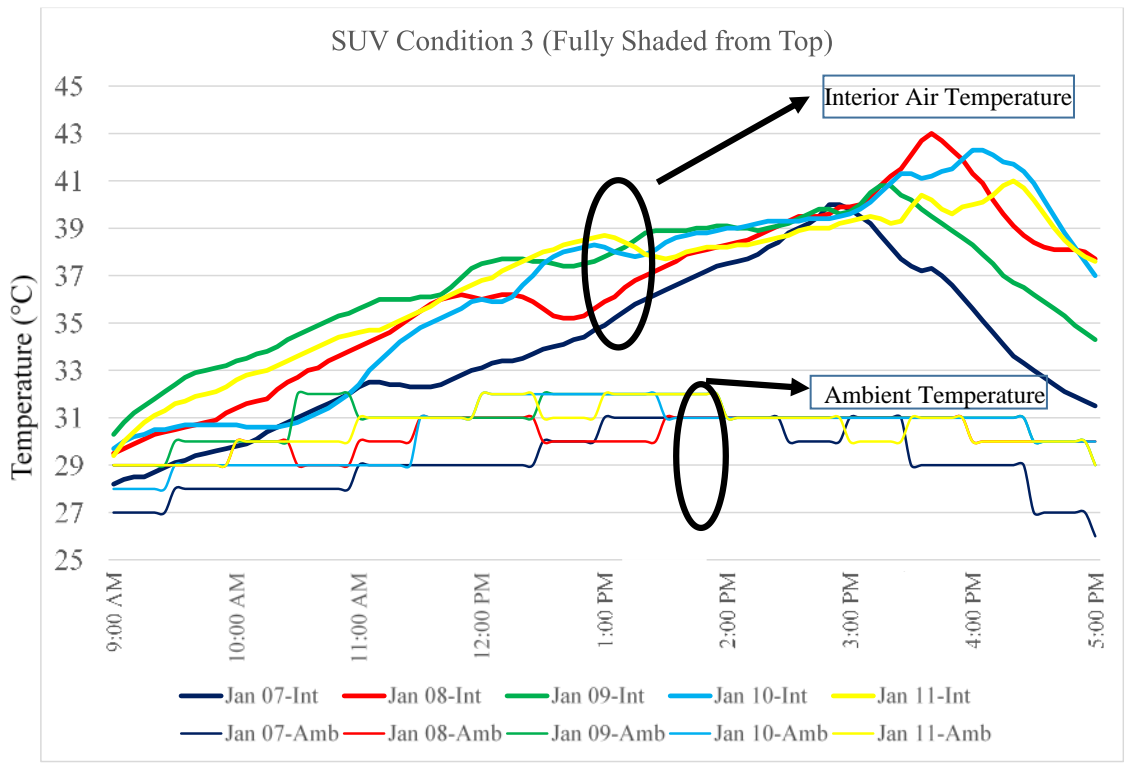

Figure15. Condition 3 for SUV type

\section{CONCLUSIONS}

The temperature investigation has been performed in three different conditions; fully shaded from the top, partially shaded and fully exposed to sunlight. When the cars were fully shaded from the top, the Saloon and the SUV reached $34.1^{\circ} \mathrm{C}$ and $43^{\circ} \mathrm{C}$ respectively. The reason of the SUV having a higher maximum temperature might be due to the bigger surface area of the windows of the SUV which leads to more sunlight entering the car especially around afternoon since the data logger was subjected to direct sunlight. When the car was partially shaded, the Saloon and the SUV reached $57.6^{\circ} \mathrm{C}$ and $57.1^{\circ} \mathrm{C}$ respectively. While they both achieved similar maximum temperature when being partially shaded, it should be noted that the rate of increase of interior air temperature was lower for the SUV. Lastly, when the car is fully exposed to sunlight, the Saloon and the SUV reached $68.7^{\circ} \mathrm{C}$ and $59.4^{\circ} \mathrm{C}$ respectively. Both the maximum temperature was very high, but the maximum temperature of the Saloon was significantly higher. This may be due to the Saloon having less volume of air in the cabin, which makes it less insulated from heat. However, it should be noted that the SUV started off with a higher interior air temperature due to it being exposed to direct sunlight in the morning. Addtionally, for all the conditions, it was observed that after exactly 4:00PM the interior air temperature showed a sharp decrease on temperature. This may suggest that the sunlight intensity decreases around this time. After observing the cars under all the different conditions, it is very clear that as long as there is presence of sunlight, the interior air temperature of the car increases well past the thermal comfort level $\left(28^{\circ} \mathrm{C}\right)$ for humans. In our next research, we are developing a mitigation technology for this problem.

\section{ACKNOWLEDGEMENT}

We would like to thanks Universiti Teknologi Brunei for financial support through final year project.

\section{REFERENCES}

1. W. A. A. Fadeel (2013). Temperature variations, inside a parked car in hot and dry climates. International Journal of Automobile Engineering, 3(1), 75-80.

2. M. Mansor et al. (2014). Variation of Car Cabin Temperature Influenced by Ventilation under Direct Sun Exposure. Journal of Mechanical Engineering and Sciences, 6, 1014-1023.

3. R. Manning and J. Ewing (2009). Temperature of Cars Study. February 2009. [Accessed: 04-May-2018].

4. M. Pešek (2013). The temperature fields measurement of air in the car cabin by infrared camera. EPJ Web of Conferences, 45, 01073.

5. S. C. Vishweshwara and J. M. A. Dhali (2013). Study of Excessive Cabin Temperatures of the Car Parked in Oman and its Mitigation. International Journal of Multidisciplinary Sciences and Engineering, 4(9).

6. D. DeMuro (2015). Car Color Test: Are Black Cars Really Hotter in the Sun?. Autotrader, August 2015, http://www.autotrader.com/car-video/car-color-test-are-black-cars-really-hotter-in-the-sun-video-242940 [Accessed: 04-May-2018].

7. H. H Al-Kayiem, et al. (2010). Study on the Thermal Accumulation and Distribution inside a Parked Car Cabin. American Journal of Applied Sciences, 7(6), 784-789.

8. C. McLaren et al. (2005). Heat Stress from Enclosed Vehicles: Moderate Ambient Temperatures Cause Significant Temperature Rise in Enclosed Vehicles, PEDIATRICS, 116(1), 109-112.

9. Grundstein et al. (2009). Maximum vehicle cabin temperatures under different meteorological conditions. International Journal of Biometeorology, 53(3), 255-261. 